\title{
HUBUNGAN ANTROPOMETRI DENGAN KURSI KERJA DI KANTOR PELAYANAN PERBENDAHARAAN NEGARA MOJOKERTO
}

\author{
RELATIONSHIP BETWEEN ANTHROPOMETRY AND WORK CHAIR \\ IN TREASURY OFFICE MOJOKERTO
}

\author{
Vrilly Andhini \\ KPU Kabupaten Mojokerto \\ E-mail: vrilly.andhini19@gmail.com
}

\begin{abstract}
Chairs are an important component in determining comfort while sitting or doing a job with sitting. The aim of the research is to analyze the suitability between the size of the table and chair with anthropometry of the employee's body. The number of respondents is 20 people. The variables of the study are measure of anthropometry and workstation. This is a descriptive research and using cross sectional approach. The measured variables are body anthropometry such as popliteal height, politeal but, hip width, shoulder height, shoulder width, elbow height. Variable work seats include seat height, seat base, length of seat base, width of seat, high backrest, width of backrest, elbow height. The results show that the dimensions of the workstation that corresponds to the body dimensions of the width of the seat base with the width of the hip the height of the backrest with the height of the sitting shoulder and the length of the elbow rest with the length of the forearm Dimensions that are inconsistent with the anthropometry of the body with the height of the chair with the popliteal height the length of the sitting base with popliteal buttock the width of the backrest with shoulder width the height of the elbow rest with the height of the sitting elbow. Conclusion is work chair is not accordance with anthropometry of employees because only 3 dimensions of work chairs are compatible with employee anthropometry.
\end{abstract}

Keywords: anthropometry, chair, dimensions

\begin{abstract}
ABSTRAK
Kursi merupakan komponen penting dalam menentukan kenyamanan saat duduk atau melakukan pekerjaan dengan duduk. Tujuan dari penelitian ini adalah menganalisis kesesuaian antara ukuran meja dan kursi dengan ukuran antropometri tubuh pegawai. Jumlah responden penelitian sebanyak 20 orang. Pengumpulan data meliputi pengukuran antropometri tubuh dan pengukuran dimensi stasiun kerja. Variabel yang diukur adalah antropometri tubuh antara lain tinggi popliteal (TPo), pantat politeal (PPo), lebar pinggul (LP), tinggi bahu duduk (TBD), lebar bahu (LB), tinggi siku duduk (TSK). Variabel kursi kerja antara lain yaitu tinggi kaki kursi (TKK), tebal alas duduk (TbAD), panjang alas duduk (PAD), lebar alas duduk (LAD), tinggi sandaran punggung (TSP), lebar sandaran punggung (LSP), tinggi sandaran siku (TSS). Hasi dari penelitian ini dimensi kursi kerja yang sesuai dengan dimensi tubuh yaitu lebar alas duduk dengan lebar pinggul (LB), tinggi sandaran dengan tinggi bahu duduk (TBD) serta panjang sandaran siku dengan panjang lengan bawah (PLB). Dimensi yang tidak sesuai dengan antropometri tubuh yaitu tinggi kaki kursi dengan tinggi popliteal (TPo), panjang alas duduk dengan pantat popliteal (PPo), lebar sandaran punggung dengan lebar bahu (LB), tinggi sandaran siku dengan tinggi siku duduk (TSK). Kesimpulan penelitian ini adalah bahwa kursi kerja tidak sesuai dengan antropometri para pegawai dikarenakan hanya 3 dimensi kursi kerja yang cocok dengan antropometri para pegawai.
\end{abstract}

Kata kunci: antropometri, dimensi, kursi

\section{PENDAHULUAN}

Semakin pesatnya era global yang semakin maju ini, kecanggihan teknologi pun sudah sangat berkembang pesat. Jika dulu kebanyakan pekerjaan dilakukan dengan manual, sekarang sudah memakai teknologi yang canggih. Tetapi dibalik itu pasti ada kekurangan dan kelebihan masing-masing. Salah satu orang yang paling merasakan dampak baik/ buruknya kemajuan teknologi tersebut adalah pekerja karena hampir $80 \%$ waktu mereka digunakan untuk bekerja.

Tenaga kerja adalah setiap orang yang mampu melakukan pekerjaan untuk menghasilkan barang ataupun jasa untuk mencukupi kebutuhan dirinya sendiri maupun orang lain. Risiko yang bisa terjadi pada pekerja saat bekerja adalah 
kecelakaan kerja dan menderita penyakit akibat kerja. Kecelakaan kerja adalah suatu kejadian yang tidak dikehendaki dan terjadi secara mendadak serta dapat menimbulkan kerugian harta benda maupun jiwa (Rachman, 1990), sedangkan penyakit akibat kerja (PAK) adalah risiko yang diterima tenaga kerja dalam bidang kesehatan yang bisa terjadi karena faktor internal (dalam diri pekerja) dan eksternal (luar diri pekerja). Dua hal tersebut bisa terjadi kapan saja dan oleh siapa saja.

Perusahaan atau instansi yang memiliki pekerja harus selalu mengantisipasi kemungkinankemungkinan sejak dini. Salah satu cara yang bisa dilakukan adalah bekerja dengan menerapkan perilaku K3. Perilaku K3 tersebut harus diterapkan dari atasan sampai bawahan dan semua orang harus mematuhinya. Perilaku K3 bisa menjadi antisipasi agar semua orang kemungkinan besar tidak mengalami hal tersebut. Penerapan Keselamatan dan Kesehatan Kerja (K3) sangat diperlukan untuk melindungi baik tenaga kerja maupun orang lain di sekitar lingkungan kerja atas hak keselamatannya pada suatu industri serta sumber industri dapat digunakan secara efisien (Suma'mur, 2009).

Di Indonesia, pemerintah telah mengeluarkan Undang-Undang No. 13 tahun 2003 tentang ketenagakerjaan yang menyebutkan bahwa setiap tenaga kerja berhak mendapatkan perlindungan atas keselamatan dan kesehatan dirinya serta moral dan perlakuan yang sama sesuai harkat dan martabat manusia. Berdasarkan hal tersebut, maka setiap perusahaan berkewajiban untuk melaksanakan sesuai dengan perundang-undangan yang telah ditetapkan tersebut guna mencapai derajat keselamatan, kesehatan dan kesejahteraan bagi para tenaga kerja dan masyarakat di sekitar lingkungan kerja. Begitu juga bagi para tenaga kerja harus menaati semua peraturan dan peraturan yang telah ditetapkan oleh perusahaan.

Berdasarkan ILO tahun 2013, pada lingkup dunia, satu pekerja meninggal setiap 15 detik akibat kecelakaan kerja, 160 pekerja mengalami sakit akibat kerja. Pada tahun sebelumnya yaitu pada tahun 2012, ILO mencatat angka kematian karena kecelakaan dan penyakit akibat kerja (PAK) sebanyak 2 juta kasus setiap tahun. Menurut Departemen Kesehatan RI tahun 2013, di Indonesia terdapat 428.844 kasus penyakit akibat kerja.

Salah satu penyakit akibat kerja yang banyak terjadi adalah nyeri punggung (back pain). Telah diketahui dengan baik bahwa keluhan muskuloskeletal (MS) membentuk masalah umum di antara tenaga kerja yang bekerja dengan computer (Collins dan O'Sullivan, 2015).

Penggunaan komputer pada generasi muda semakin meluas. Tentu saja kejadian dan efek MS di kalangan mahasiswa telah menjadi lebih banyak terjadi. Hamilton dkk. (2005) ditemukan prevalensi MS terkait komputer menjadi $80,6 \%$ di antara mahasiswa perempuan di sebuah universitas di Amerika Serikat. Dua penelitian lain menemukan prevalensi MS di antara mahasiswa menjadi 96\% (Chang dkk., 2007) dan $86 \%$ pria (Menendez dkk., 2007) di antara mahasiswa yang ditemui.

KPPN Mojokerto adalah salah satu lembaga di instansi pemerintahan berada langsung di bawah Kantor Wilayah IX Direktorat Jenderal Anggaran Surabaya, Direktorat Jenderal Anggaran, Departemen Keuangan Republik Indonesia. Komputer sudah tidak dapat terpisahkan lagi dari pekerjaan di sana. Seiring perkembangan jaman, KPPN Mojokerto juga mengikuti kemajuan teknologi dengan digunakannya komputer untuk mempermudah pekerjaan. Begitu risiko mengalami PAK terutama nyeri punggung lebih besar. Sebuah tinjauan studi epidemiologi oleh Punnett dan Bergqvist (1997) menemukan bahwa bekerja dengan komputer menunjukkan risiko gangguan pada leher, bahu, lengan, pergelangan tangan lebih tinggi dan tangan dibandingkan dengan pekerja yang bekerja tanpa menggunakan komputer.

Kursi merupakan komponen penting dalam menentukan kenyamanan saat duduk atau melakukan pekerjaan dengan duduk. Sehingga kursi berinteraksi langsung dengan manusia. Sama halnya dengan Computer Workstations berinteraksi dengan pengguna, dengan demikian, desain interaksi ini menentukan kenyamanan dan kinerja pengguna. Ha"nninen dan Koskelo (2003) menemukan bahwa ketegangan pada otot lumbal secara signifikan berkurang di kalangan siswa SMA yang menggunakan Meja dan kursi yang dapat disesuaikan. Toomingas dan Gavhed (2008) melakukan penelitian terhadap operator call center, dan menyimpulkannya bahwa dengan Penyesuaian kursi yang optimal dapat mengurangi terjadinya sakit pada leher/skapula dan punggung.

Ergonomi atau ergonomic berasal dari bahasa yunani yaitu ergo yang berarti kerja dan nomos yang berarti hukum. Ergonomi dapat diartikan sebagai disiplin ilmu yang ada kaitannya dengan pekerjaan (Wignjosoebroto, 1995). Ergonomi atau yang biasa disebut human engineering juga didefinisikan sebagai ilmu, seni dan penerapan teknologi untuk 
menyeimbangkan antara segala fasilitas yang digunakan oleh manusia baik saat beraktivitas maupun istirahat dengan segala kemampuan maupun keterbatasan manusia secara fisik maupun mental sehingga tercapai kualitas hidup manusia yang lebih baik (Tarwaka, dkk., 2004). Maksud dari ergonomi adalah mengetahui masalah-masalah tentang interaksi manusia dengan teknologi dan produk-produknya. Sehingga dimungkinkan adanya suatu rancangan sistem manusia-teknologi yang optimal (Wignjosoebroto, 1995).

Tuntutan kerja dengan kapasitas kerja harus selalu dalam garis keseimbangan sehingga dapat menghasilkan performansi yang tinggi. Tuntutan kerja tidak boleh terlalu rendah (underload) maupun terlalu tinggi (overload) karena keduanya sama-sama dapat menyebabkan stres kerja.

Begitu juga dengan perancangan kursi yang ergonomis. Hal ini difokuskan pada mekanisme untuk beberapa posisi kerja dan fleksibilitas dari workstation. Apalagi bentuk/ dimensi masing-masing bagian juga dipertimbangkan dalam prosedur perancangan. Desain kursi kerja tersebut akan dibuat sesuai dengan antropometri penggunanya.

Antropometri berasal dari kata "anthro" yang berarti manusia dan "metri" yang berarti ukuran. Sehingga antropometri dapat didefinisikan sebagai suatu studi yang berkaitan dengan pengukuran dimensi tubuh manusia. Data anthropometri yang didapat bisa diaplikasikan salah satunya untuk perancangan area kerja, peralatan kerja dan perancangan produk-produk konsumtif seperti meja dan kursi. Dimensi tubuh dari populasi pengguna sangat penting dalam desain stasiun kerja (Helander dkk., 1987). Nissinen dkk (1994) menyatakan bahwa pengukuran antropometri yang telah dilakukan untuk menjadi prediktor low back pain meski tidak terlalu berperan penting. Menurut Balague dkk. (1993), parameter antropometri adalah salah satu faktornya terkait dengan nyeri punggung bagian bawah. Antropometri akan menentukan bentuk, ukuran dan dimensi yang tepat untuk produk yang dirancang/ digunakan oleh manusia tersebut.

Faktor-faktor yang mempengaruhi variasi dimensi tubuh manusia diantaranya (Wignjosoebroto, 1995) usia, jenis kelamin, suku bangsa (etnis) dan ras, pekerjaan. Pada faktor usia, Ukuran tubuh manusia akan berkembang dari saat lahir sampai berumur 20-25 tahun dan mulai menurut setelah usia 35-40 tahun. Pada faktor jenis kelamin, kebanyakan ukuran tubuh pria lebih besar dari pada wanita kecuali pada bagian pinggul dan pantat. Faktor suku bangsa (etnis) dan ras, manusia yang berbeda etnis dan ras mempunyai ukuran perbedaan dimensi tubuh yang sangat signifikan. Faktor pekerjaan, aktivitas kerja sehari hari juga menyebabkan perbedaan ukuran tubuh manusia. Pemain basket profesional biasanya lebih tinggi dari orang biasa.

Agar rancangan produk sesuai dengan ukuran manusia yang akan mengoperasikannya maka prinsip-prinsip yang harus ditetapkan yaitu (Wignjosoebroto, 1995) prinsip perancangan produk bagi individu dengan ukuran yang Ekstrem dibuat agar bisa memenuhi 2 sasaran produk, prinsip perancangan produk yang bisa dioperasikan di antara rentang ukuran tertentu. Rancangan bisa diubah-ubah sehingga lebih fleksibel. Yang terakhir adalah prinsip perancangan produk dengan ukuran rata-rata. Produk ini dirancang dan dibuat untuk mereka yang berukuran sekitar atau rata-rata. Sehingga bagi yang memiliki ukuran tubuh ekstrim akan dibuat rancangan sendiri.

Berkaitan dengan aplikasi data antropometri yang diperlukan dalam proses perancangan produk ataupun fasilitas kerja, maka ada beberapa saran / rekomendasi yang diberikan sesuaikan dengan langkah yaitu (Wignjosoebroto, 1995) yang pertama adalah menetapkan anggota tubuh yang mana yang amati dan akan difungsikan untuk mengoperasikan rancangan tersebut. Kemudian tentukan dimensi tubuh yang penting dalam proses perancangan tersebut. Hal ini yang harus diperhatikan juga adalah apakah harus menggunakan data structural body dimension atau Functional dimension. Kemudian tentukan populasi terbesar yang harus diantisipasi, diakomodasikan dan menjadi target utama pemakai rancangan produk tersebut. Tetapkan prinsip ukuran yang harus diikuti semisal apakah rancangan tersebut untuk ukuran individual yang ekstrem, rentang ukuran yang fleksibel (adjustable) ataukah ukuran rata-rata. Pilihlah presentase populasi yang harus diikuti misalnya 90-th, 95-th, 99-th atau dinilai persentil lain yang dikehendaki. Setiap dimensi tubuh yang telah diidentifikasi selanjutnya pilih atau tetapkan nilai ukurannya dari tabel data antropometri yang sesuai. Aplikasikan data tersebut dan tambahkan faktor kelonggaran (allowance) bila diperlukan seperti halnya tambahan ukuran akibat faktor tebalnya pakaian yang harus dikenakan oleh operator.

Menurut Suma'mur (1996) ada beberapa prinsip ergonom yang dapat digunakan dalam program kesehatan kerja. yang pertama adalah sikap tubuh saat melakukan pekerjaan sangat dipengaruhi 
oleh bentuk, susunan, ukuran dan penempatan mesin-mesin, penempatan alat-alat penunjuk, caracara menggunakan mesin (macam gerak, arah, kekuatan, dan lain sebagainya). Kedua, standarisasi bentuk dan ukuran mesin serta peralatan kerja, harus diambil ukuran terbesar sebagai dasar, serta diatur dengan suatu cara sehingga ukuran tersebut dapat dikecilkan dan dapat digunakan oleh tenaga kerja yang lebih kecil. Ketiga, ukuran-ukuran antropometri yang dapat dijadikan dasar untuk penempatan alat-alat kerja. Keempat, pekerjaan manual yang dilakukan dengan cara berdiri, tinggi meja kerja harus 5-10 $\mathrm{cm}$ di bawah tinggi siku. Selanjutnya, dari segi otot, sikap duduk yang paling baik adalah sedikit membungkuk, sedangkan dari sudut tulang, dianjurkan duduk tegak agar punggung tidak membungkuk dan otot perut tidak lemas, maka dianjurkan pemilihan sikap duduk yang tegak yang baik diselingi istirahat sedikit membungkuk. Berikutnya, tempat duduk yang memenuhi syarat sebagai berikut: Tinggi dataran duduk dapat diatur dengan papan pijakan kaki sehingga sesuai dengan tinggi lutut, sedangkan paha berada dalam keadaan datar, tinggi papan sandaran punggung dapat diatur dan dapat menekan pada punggung, lebar alas duduk seharusnya tidak kurang dari lebar terbesar ukuran antropometri pinggul misalnya lebih dari $40 \mathrm{~cm}$.

Prinsip selanjutnya adalah pekerjaan yang dilakukan sambil berdiri, maka disediakan tempat duduk dan kesempatan untuk beristirahat. Berikutnya, arah penglihatan untuk pekerjaan berdiri adalah 23-37 derajat ke bawah, sedangkan untuk pekerjaan duduk arah penglihatan antara 32-44 derajat ke bawah. Arah penglihatan ini sesuai dengan sikap kepala yang istirahat. Kemampuan seseorang bekerja adalah 8-10 jam per hari. Lebih dari itu efisiensi dan efektivitas kerja menurun. Lalu ruang gerak lengan ditentukan oleh punggung lengan dan lengan bawah. Pegangan-pegangan harus diletakkan pada daerah tersebut, terutama bila sikap tubuh tidak berubah. Jenis gerakan yang terus menerus dan berirama lebih diutamakan. Beban tambahan akibat lingkungan kerja fisik, mental-psikologis dan sosial sebaiknya sedapat mungkin dikurangi. Kemampuan beban fisik maksimal oleh ILO ditentukan sebesar $50 \mathrm{~kg}$. Pemeliharaan indera penglihatan dilakukan sebaik-baiknya terutama dengan penyelenggaraan pencahayaan dan penerangan yang baik.

Adanya kesesuaian antara alat kerja yaitu kursi dengan bentuk tubuh para pekerja sangat penting. Latar belakang yang ada inilah yang membuat peneliti ingin meneliti hal tersebut. Tujuan dari penelitian ini adalah mempelajari kesesuaian antara kursi kerja dengan antropometri tubuh para pegawai di KPPN Mojokerto.

\section{METODE}

Penelitian ini dilakukan dengan survey pada pegawai KPPN Mojokerto. Pengambilan data dilakukan sebanyak 1 kali. Sampel yang digunakan yaitu seluruh pegawai di KPPN Mojokerto pada bagian front office dan middle office yang berjumlah 20 orang.

Variabel yang diukur adalah 1. Antropometri Tubuh antara lain Tinggi Popliteal (TPo), Pantat Politeal (PPo), Lebar Pinggul (LP), Tinggi bahu duduk (TBD), Lebar bahu (LB), Tinggi siku duduk (TSK). 2. Kursi kerja antara lain yaitu Tinggi kaki kursi (TKK), Tebal alas Duduk (TbAD), Panjang Alas Duduk (PAD), Lebar Alas Duduk (LAD), Tinggi Sandaran Punggung (TSP), Lebar Sandaran Punggung (LSP), Tinggi sandaran siku (TSS). Setelah pengukuran dilakukan, data antropometri akan diolah untuk mendapatkan nilai rata-rata, standar deviasi, 5\%-ile dan 95\%-ile pada setiap dimensi tubuh. Kemudian akan dicari hubungan dengan kursi kerjanya

\section{HASIL}

\section{Pengukuran Antropometri}

Pada Tabel 1 dapat diketahui standar deviasi, 5\%-ile, nilai rata-rata, dan 95\%-ile dari semua variabel antropometri yang diukur. Untuk TPo responden pada penelitian ini adalah sebesar 30, 371 $\mathrm{mm}, 420 \mathrm{~mm}$ dan $469 \mathrm{~mm}$. Ukuran panjang pantat popliteal (PPo) yaitu 23, $321 \mathrm{~mm}, 359 \mathrm{~mm}$ dan $397 \mathrm{~mm}$. Ukuran lebar pinggul (LP) adalah 23, $321 \mathrm{~mm}, 359 \mathrm{~mm}$ dan $397 \mathrm{~mm}$. Ukuran tinggi

Tabel 1. Ukuran Antropometri

\begin{tabular}{lcccc}
\hline \multicolumn{1}{c}{ Variabel Pengukuran } & sd & P5 & $\begin{array}{c}\text { X/ } \\
\text { P50 }\end{array}$ & P95 \\
\hline Tinggi popliteal (TPo) & 30 & 371 & 420 & 469 \\
Pantat politeal (PPo) & 27 & 405 & 451 & 495 \\
Lebar pinggul (LP) & 23 & 321 & 359 & 397 \\
Bahu duduk (LB) & 33 & 477 & 532 & 587 \\
Lebar bahu (LB) & 27 & 380 & 425 & 469 \\
Tinggi siku duduk (TSK) & 32 & 175 & 227 & 279 \\
Panjang lengan bawah (PLB) & 18 & 403 & 434 & 464 \\
\hline
\end{tabular}


bahu duduk (TBD) adalah 33, $477 \mathrm{~mm}, 532 \mathrm{~mm}$ dan $587 \mathrm{~mm}$. Ukuran lebar bahu (LB) adalah 27, 380 $\mathrm{mm}, 425 \mathrm{~mm}$ dan $469 \mathrm{~mm}$ tinggi siku duduk (TSK) adalah 32, $175 \mathrm{~mm}, 227 \mathrm{~mm}$ dan $279 \mathrm{~mm}$. Ukuran panjang lengan bawah (PLB) pria adalah 18, 403 $\mathrm{mm}, 434 \mathrm{~mm}$ dan $464 \mathrm{~mm}$.

Tabel 1 adalah hasil pengukuran antropometri dari 6 variabel.

Gambar dimensi antropometri yang diukur dalam penelitian ini bisa dilihat mulai Gambar 1-7.

Dari semua variabel antropometri pada Tabel 1, bila mengacu pada Himpunan Ergonomi Indonesia (2016) terdapat 3 dimensi antropometrinya lebih kecil dari pada rata-rata ukuran orang Indonesia. 3 dimensi antropometri tersebut adalah tinggi popliteal (TPo), tinggi bahu duduk (TBD) serta tinggi siku duduk (TSK). Sedangkan dimensi antropometri yang lebih besar dari pada rata-rata ukuran orang Indonesia. Dimensi antropometri tersebut antara lain pantat popliteal (PPo), lebar pinggul (LB), lebar bahu (LB), panjang lengan bawah (PLB).

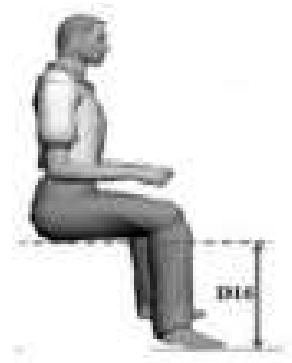

Gambar 1. Dimensi Tinggi Popliteal (Tpo).

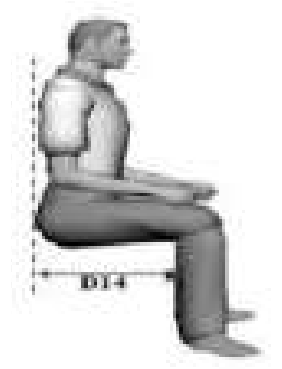

Gambar 2. Dimensi Pantat Popliteal (PPo).

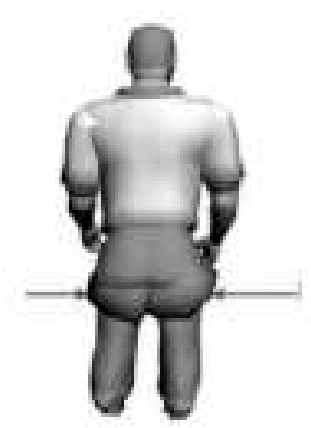

Gambar 3. Dimensi Lebar Pinggul (LP).

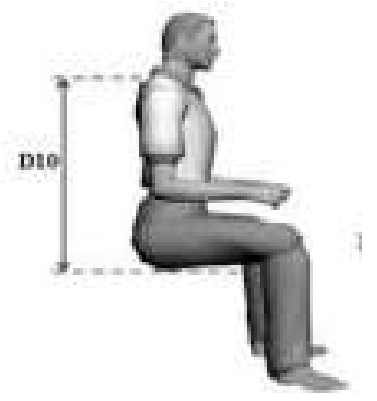

Gambar 4. Dimensi Tinggi Bahu Duduk (TBD).

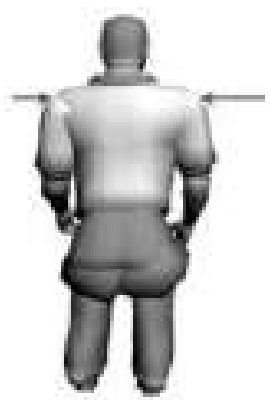

Gambar 5. Dimensi Lebar Bahu (LB).

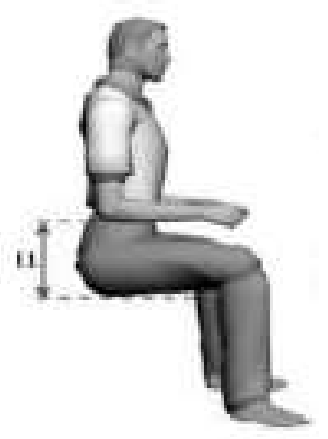

Gambar 6. Dimensi Tinggi Siku Duduk (TSK). 


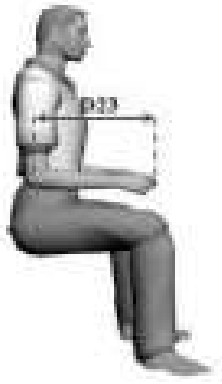

Gambar 7. Dimensi Panjang Lengan Bawah (PLB).

\section{Pengukuran Kursi Kerja}

Kursi kerja yang digunakan di kantor KPPN Mojokerto hanya terdapat 1 jenis saja. Sehingga pengukuran dilakukan sebanyak 1 kali. Gambar dimensi kursi yang diukur di KPPN Mojokerto pada Gambar 8.

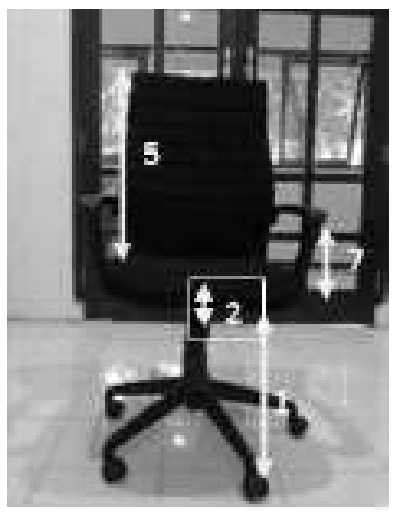

Gambar 8. Dimensi kursi 1.

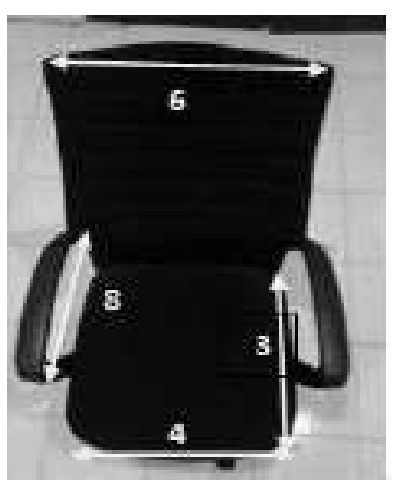

Gambar 9. Dimensi kursi 2.

Pada Tabel 2 dapat diketahui bahwa tinggi kaki kursi kerja adalah $385 \mathrm{~mm}-445 \mathrm{~mm}$. Panjang alas
Tabel 2. Ukuran Dimensi Kursi

\begin{tabular}{lc}
\hline \multicolumn{1}{c}{ Dimensi kursi } & Hasil Pengukuran \\
\hline Tinggi kaki kursi & $385-445 \mathrm{~mm}$ \\
Tebal alas duduk & $50 \mathrm{~mm}$ \\
Panjang alas duduk & $430 \mathrm{~mm}$ \\
Lebar alas duduk & $470 \mathrm{~mm}$ \\
Tinggi sandaran & $610 \mathrm{~mm}$ \\
Lebar sandaran & $450 \mathrm{~mm}$ \\
Tinggi sandaran siku & $190 \mathrm{~mm}$ \\
Panjang sandaran siku & $310 \mathrm{~mm}$ \\
\hline
\end{tabular}

duduk adalah $430 \mathrm{~mm}$. Lebar alas duduk adalah $470 \mathrm{~mm}$, lalu tinggi sandaran duduk adalah $610 \mathrm{~mm}$. Lebar sandaran adalah $450 \mathrm{~mm}$. Tinggi sandaran siku adalah $190 \mathrm{~mm}$ dan yang terakhir, panjang sandaran siku adalah $310 \mathrm{~mm}$.

\section{PEMBAHASAN}

Penelitian ini, hasil yang didapat dalam perbandingan antara antropometri dengan dimensi kursi ada yang sesuai dan ada yang tidak sesuai. Berikut adalah pembahasan pada setiap dimensi kursi.

\section{Hubungan Tinggi Popliteal (TPo) dengan Tinggi Kaki Kursi}

Tinggi kaki kursi memiliki peran yang cukup penting dalam memberikan kenyamanan bagi para penggunanya. Tinggi kursi harus memungkinkan kaki pengguna saat duduk merasa nyaman yang didukung dengan lantai/pijakan kaki yang tepat. Lueder (1994) menyatakan bahwa penyesuaian ketinggian kursi adalah elemen terpenting dari sebuah tempat kerja. Penelitian Hira (1980), dikatakan bahwa jika tinggi alas duduk terlalu rendah, ada kecenderungan kuat bagi pengguna untuk membungkuk, mendorong kaki mereka ke depan dan menjadi gangguan bagi orang lain, sedangkan kursi tidak nyaman jika terlalu tinggi. Ketinggian kursi yang optimal harus tidak berbeda jauh dengan ketinggian popliteal (Pheasant, 2005). Sementara itu, Pheasant (2005) berpendapat bahwa tinggi kursi yang optimal harus tidak berbeda jauh dengan ketinggian popliteal.

Menurut Humantech (1995), ukuran tinggi kaki kursi yang diusulkan adalah $40-52 \mathrm{~cm}$ atau 400-520 mm. Menurut BIFMA (2006), tinggi kaki kursi kantor sekitar 381-505 mm. Hasil 
pengukuran bahwa dimensi tinggi kaki kursi yang telah ditambahkan dengan tebal alas duduk adalah 435-495 mm.

Pada hasil pengukuran antropometri yang digunakan, Thariq, dkk (2010) merekomendasikan menggunakan persentil ke-5 sebagai ukuran terkecil ditambah toleransi untuk sepatu sebesar $4,5 \mathrm{~mm}$ sehingga didapatkan ukuran $375,5 \mathrm{~mm}$. Disimpulkan bahwa tinggi kursi kantor kurang cocok dengan antropometri karena kaki kursi terlalu tinggi. Keadaan kursi di sini tidak sesuai dengan pendapat peneliti yang percaya bahwa kursi harus lebih rendah dari ketinggian popliteal sehingga setiap tekanan di bawah paha dihindari (Dul dan Weerdmeester, 1998). Penelitian lain menunjukkan bahwa lebih mudah bagi orang yang tinggi untuk di adaptasi ke tempat duduk rendah daripada orang pendek yang di adaptasi menjadi tempat duduk yang tinggi.

\section{Hubungan Panjang Pantat Popliteal (PPo) dengan Panjang Alas Duduk}

Grimes dan Legg (2004) menyatakan bahwa ketidaksesuaian antara panjang pantat politeal dan panjang alas duduk secara signifikan memengaruhi kenyamanan saat duduk. Menurut BIFMA (2006) panjang alas duduk yang diusulkan adalah tidak lebih dari 16,9 inci atau sekitar $429 \mathrm{~mm}$. Hasil pengukuran dimensi kursi yaitu panjang alas duduk didapatkan adalah $430 \mathrm{~mm}$.

Hasil pengukuran antropometri yang digunakan, Thariq, $d k k$ (2010) merekomendasikan menggunakan persentil ke-5. Pada sebagian besar peneliti sepakat dalam menentukan panjang kursi harus digunakan 5\%-ile panjang pantat politeal, bahkan untuk pengguna paling pendek (Gouvali dan Boudolos, 2005) sehingga didapatkan hasil 405 $\mathrm{mm}$. Perbedaan panjang alas duduk dengan panjang pantat politeal memiliki beda $25 \mathrm{~mm}$ atau $2,5 \mathrm{~cm}$. Hal ini berlawanan dengan pendapat dari Poulakakis dan Marmaras (1998) menyebutkan bahwa panjang alas duduk minimal $5 \mathrm{~cm}$ lebih pendek dari panjang pantat popliteal (PPo). Panjang alas duduk kursi yang dipakai tidak sesuai dengan antropometri para pegawai.

\section{Kesesuaian Lebar Pinggul (LP) dengan Lebar Alas Duduk}

Lebar alas duduk seharusnya cukup besar untuk dapat menampung pengguna dengan luas pinggul terbesar (Evans dkk., 1988). Saran dari Thariq, dkk (2010) menyatakan bahwa lebar kursi harus sebesar 10\% hingga 30\% dari lebar pinggul. Usulan lebar alas duduk menurut BIFMA (2006) untuk lebar alas duduk adalah tidak kurang dari 18 inci atau $457 \mathrm{~mm}$. Hasil pengukuran antropometri yang digunakan, Thariq, $d k k$ (2010) merekomendasikan menggunakan persentil ke-95 ditambah toleransi sebesar $40 \mathrm{~mm}$ dengan tujuan agar pegawai yang mempunyai pinggul yang besar masih bisa duduk dengan nyaman karena secara anatomi, perempuan memiliki pinggul yang lebih besar dari pada laki-laki sehingga didapatkan hasil $437 \mathrm{~mm}$. Dari hasil tersebut dapat disimpulkan bahwa kursi yang dipakai sudah sesuai dengan antropometri pegawai.

\section{Kesesuaian Tinggi Bahu Duduk (TBD) dengan Tinggi Sandaran Kursi}

Sandaran punggung yang baik adalah sandaran yang dapat memberikan kenyamanan pada dan sesuai dengan kontur tulang belakang. Semakin tinggi sandaran kursi dinilai semakin baik, karena dapat mengurangi beban atau kinerja dari lumbar yang berlebihan untuk menjaga postur tulang belakang. Evans, $d k k$ (1988) yang mengatakan bahwa tinggi sandaran kursi dianggap tepat bila berada di bawah scapula/ tulang belikat. Direkomendasikan sandaran punggung lebih rendah dari skapula, atau maksimal di atas tepi skapula (60-80\% tinggi bahu).

Sandaran punggung dapat dibedakan menjadi 3 jenis. Masing-masing jenis tersebut disesuaikan dengan keadaan tertentu. Adapun jenisnya sebagai berikut (Pheasant, 2005) yaitu sandaran tingkat rendah, sandaran tingkat menengah dan sandaran tingkat tinggi. Sandaran tingkat rendah adalah sandaran yang dapat memberikan dukungan untuk lumbalis dan torakalis sehingga memungkinkan kebebasan bergerak untuk bahu dan lengan. Sandaran tingkat menengah berfungsi juga untuk menopang bahu. Yang termasuk dalam kategori sandaran tingkat menengah adalah kursi kantor modern dan kursi auditorium. Ketinggian yang dianjurkan dari jenis sandaran ini adalah sekitar $500 \mathrm{~mm}$. Sandaran tingkat tinggi berguna untuk menopang kepala dan leher penuh. Rekomendasi tinggi sandaran jenis ini adalah $900 \mathrm{~mm}$.

Usulan yang diberikan oleh BIFMA (2006) untuk tinggi sandaran kursi adalah sekitar 14,2 inci atau sekitar $310 \mathrm{~mm}$. Menurut Humantech (1995), ukuran tinggi sandaran punggung yang diusulkan adalah $>35 \mathrm{~cm}$. Hasil pengukuran dimensi tinggi sandaran kursi adalah $610 \mathrm{~mm}$. Sedangkan hasil pengukuran antropometri yang dipakai, Thariq, $d k k$ (2010) merekomendasikan menggunakan persentil 
ke-5 yaitu $477 \mathrm{~mm}$. Dari hasil tersebut diketahui bahwa tinggi sandaran kursi yang ada sudah sesuai dengan antropometri pegawai baik untuk ukuran tubuh kecil maupun besar.

\section{Kesesuaian Lebar Bahu dengan Lebar Sandaran Kursi}

Menurut Humantech (1995), ukuran standar untuk lebar sandaran adalah 45-55 cm. Pulat (1992), menyatakan bahwa lebar sandaran yang ideal adalah $33 \mathrm{~cm}$. Menurut BIFMA (2006), lebar sandaran yang dianjurkan adalah sekitar 14,2 inci atau sekitar 360 $\mathrm{mm}$.

Hasil dari pengukuran dimensi lembar sandaran kursi adalah $450 \mathrm{~mm}$. Berdasarkan penelitian dari Thariq $d k k$ (2010), merekomendasikan penggunaan persentil ke 95 ditambahkan toleransi sebesar 40 mm. Sehingga apabila memakai acuan penelitian ini maka data antropometri yang dipakai $509 \mathrm{~mm}$. Jadi lebar sandaran kursi yang tidak sesuai dengan antropometri lebar bahu para pegawai.

\section{Kesesuaian Tinggi Siku Duduk dengan Tinggi Sandaran Siku}

Nag dkk (2008), menyatakan bahwa komponen sandaran kursi Memiliki kontribusi besar untuk mengurangi bobot pada panel kursi dan mengurangi stres di tulang belakang dan struktur lainnya. Armrests dapat memberikan dukungan postural tambahan dan menjadi bantuan untuk berdiri dan duduk (Pheasant, 2005). Pada kursi biasa, tidak terdapat sandaran lengan. Kursi kantor pada umumnya terdapat sandaran lengan. Beberapa pengguna komputer, sering memanfaatkan sandaran lengan untuk mengurangi beban statis pada otot leher (Pheasant, 2005)

Ukuran tinggi siku duduk digunakan untuk membandingkan dengan tinggi sandaran siku. Menurut Humantech (1995), mengusulkan ukuran tinggi sandaran lengan adalah 15-17,5 cm. Sedangkan menurut BIFMA (2006) merekomendasikan tinggi sandaran siku yaitu sekitar 6.9-10.8 inci atau sekitar 175-275 mm. Dari hasil pengukuran tinggi sandaran siku didapatkan sebesar $190 \mathrm{~mm}$.

Hasil penelitian dari Thariq $d k k$ (2010) merekomendasikan tinggi sandaran siku adalah sejajar dengan tinggi siku duduk. Penelitian Ismaila dan Musa (2013) merekomendasikan menggunakan persentil ke-5. Mengacu pada penelitian Ismaila dan Musa (2013), maka hasil pengukuran yang dipakai adalah persentil ke-5 yaitu $175 \mathrm{~mm}$. Dapat disimpulkan bahwa tinggi sandaran siku kurang sesuai dengan sebagian antropometri para pegawai.

\section{Kesesuaian Panjang Lengan Bawah dengan Panjang Sandaran Siku}

Beberapa pendapat memberikan bermacammacam rekomendasi terkait dengan ukuran dari panjang lengan bawah. US Army Natick menyarankan panjang sandaran kursi 4 inci atau sekitar $10 \mathrm{~cm}$ lebih pendek dari pada panjang lengan (US Army Natick, 1989). Menurut Humantech (1995), ukuran panjang sandaran lengan yang diusulkan adalah $15 \mathrm{~cm}$.

Hasil pengukuran kursi kerja, didapatkan hasil $310 \mathrm{~mm}$. Thariq dkk (2010), merekomendasikan penggunaan persentile ke-50 atau sama saja dengan menggunakan mean $(\mathrm{X})$ jadi ukuran antropometri yang dibandingkan adalah sebesar $434 \mathrm{~mm}$. Panjang sandaran lengan sudah sesuai dengan antropometri lengan bawah para pegawai.

\section{SIMPULAN}

Simpulan dari penelitian ini didapatkan bahwa terdapat 3 dimensi kursi kerja yang sesuai dengan antropometri pegawai di KPPN Mojokerto yaitu lebar alas duduk yang tidak sesuai dengan 95\%-ile keseluruhan lebar pinggul (LB) para pegawai, tinggi sandaran sesuai dengan 5\%-ile keseluruhan tinggi bahu duduk (TBD) para pegawai. Serta panjang sandaran siku sesuai dengan rata-rata panjang lengan bawah (PLB) keseluruhan para pegawai.

Terdapat 4 dimensi kursi kerja yang tidak sesuai dengan antropometri tubuh yaitu tinggi kaki kursi tidak sesuai dengan 5\%-ile keseluruhan tinggi popliteal (TPo) para pegawai, panjang alas duduk tidak sesuai dengan $5 \%$-ile pantat popliteal (PPo), lebar sandaran punggung tidak sesuai dengan 95\%-ile keseluruhan lebar bahu (LB) para pegawai, serta tinggi sandaran siku tidak sesuai dengan 5\%-ile keseluruhan tinggi siku duduk (TSK) para pegawai.

\section{DAFTAR PUSTAKA}

Balague, F., Daminot, P., Nordin, M., 1993. CrossSectional Study of the Isokinetic Muscle Trunk Strength Among School-Children. Spine 18, 1199-1205.

Business and Institutional Furniture Manufacturers Association International., 2002. Ergonomics 
Guidelines for VDT (Video Display Terminal) Furniture Used in Office Workspace. Michigan: BIFMA International.

CEN., 2000. Office Furniture: Office work Chair. Brussels: European Committee for Standardization.

Chang, C.J., 2007. Daily Computer Usage Correlated with Undergraduate Students' Musculoskeletal Symptoms. Am. J. Ind. Med. 50: 481-488.

Collins, J.D., O'Sullivan, L.W., 2015. Musculoskeletal Disorder Prevalence and Psychosocial Risk Exposures by Age and Gender in a Cohort of Office Based Employees in Two Academic Institutions. Int. J. Ind. Ergon. 46: 85-97.

Dul, J., Weerdmeester, B (eds)., 1998. Posture and Movement. Ergonomics for Beginners. London: Taylor \& Francis.

Evans, W.A., Courtney, A.J., Fok, K.F., 1988. The Design of School Furniture for Hong Kong School Children: An Anthropometric Case Study. Appl. Ergonom, [e-journal] 19, 122-134.

Gouvali, M.K., Boudolos., 2005.Match between School Furniture Dimensions and Children's Anthropometry. International Journal of Industrial Ergonomics. [e-journal] 37 (2006): 765-773.

Grimes, P., Legg, S., 2004. Musculoskeletal Disorders (MSD) in Students as a Risk Factor for Adult MSD: A Review of The Multiple Factors Affecting Posture, Comfort and Health in Classroom Environments. Journal of the Human Environmental System, [e-journal] 7 (1), 1-9.

Hamilton, A., Jacobs, K., Orsmond, G., 2005. The Prevalence of Computer-Related Musculoskeletal Complaints in Female College Students. Work 24, [e-journal] 387-394.

Ha”nninen, O., Koskelo, R., 2003. Adjustable Table and Chairs Correct Posture Lower Muscle Tension and Pain in High School Students. In: Proceedings of the XVth Triennial Congress of the International Ergonomics Association. Seoul, Korea.

Helander, M.G., Czaja, S.J., Drury, C.G., Cary, J.M., 1987. An Ergonomic Evaluation of Office Chairs. Office: Technology and People 3: 247-262.

Himpunan Ergonomi Indonesia., 2013. Data Antropometri. Tersedia di http:// antropometriindonesia.org/index.php/detail/ artikel/4/10/data_antropometri

Hira, D., 1980. An Ergonomic Appraisal of Educational Desks. Ergonomics 23, 213-222.
Humantech Inc., 1995. Humantech Ergonomics Training Manual: Prepared for Procter \& Gamble Inc. Australia: Berkeley Vale.

ILO., 2013. Health and Safety in Work Place for Productivity. Geneva: International Labour Office.

Ismaila, S.O., Musa, A.I., 2013. Anthropometric Design of Furniture for Use in Tertiary Institutions in Abeokuta, South-Western Nigeria. International Journal of Industrial Ergonomics,[e-journal] 33 (3): 179-192. Tersedia di: hrcak.srce.hr/ file/163753 [Sitasi 3 Juni 2017].

Lueder, R., 1994. Hard Facts About Soft Machine. UK: Taylor \& Francis.

Menendez, C.C., 2007. A Multi-Method Study Evaluating Computing-Related Risk Factors Among College Students. WORK. [e-journal] 28(4), 287-297.

Nag, P.K., Pal, S., Kotadiya, S.M., Nag, A., Gosai, K., 2008. Human-Seat Interface Analysis of Upper and Lower Body Weight Distribution. International Journal of Industrial Ergonomics, [e-journal] 38 (5), 539-545.

Pheasant, S., 2005. Ergonomics in The Office. Dalam: Bodyspace: Anthropometry, Ergonomics, and The Design of Work. Haslegrave, R.C. ed. Journal Ergonomic. pp. 161-181.

Poulakakis, G., Marmaras, N., 1998. A Model for the Ergonomic Design of Office. In: Scott, P.A., Bridger, R.S., Charteris, J. (Eds.), Proceedings of the Ergonomics Conference in Cape Town: Global Ergonomics. Elsevier Ltd., pp. 500-504.

Pulat, B.M., 1992. Fundamentals of Industrial Ergonomics. New Jersey: Prentice-Hall International.

Punnett, L., Bergqvist, U., 1997. Visual Display Unit Work and Upper Extremity Musculoskeletal Disorders: a Review of Epidemiological Findings. Sweden: Ergonomic Expert Committee, Tersedia di https://pdfs.semanticscholar.org/f9cc/8c66f3a e036043ec6d06b52bfef04e6cac37.pdf [sitasi 20 Juli 2017].Rachman, A., 1990. Pedoman Studi Hiperkes pada Institusi Pendidikan Tenaga Sanitasi. Jakarta: Depkes RI, Pusdiknakes

Suma'mur P.K., 1996. Higiene Perusahaan dan Kesehatan Kerja. Jakarta: PT. Gunung Agung.

Tarwaka., Sholichul., Lilik, S., 2004. Ergonomi untuk Keselamatan, Kesehatan Kerja dan Produktivitas. Surakarta: UNIBA Press.

Thariq, M.G., Munasinghe, H.P., Abeysekara, J.D., 2009. Designing Chairs with Mounted Desktop 
for University Student: Ergonomics and Comfort. International Journal of Industrial Ergonomics. [e-journal] 40 (2010): 8-18.

Toomingas, A., Gavhed, D., 2008. Workstation Layout and Work Postures at Call Centres in Sweden in Relation to National Law, EU-Directives and ISO-Standards, and to Operators' Comfort and Symptoms. International Journal of Industrial Ergonomics, 38 (11), 1051-1061.
Undang-Undang Republik Indonesia Nomor 13 Tahun 2003. Tentang Ketenagakerjaan. Jakarta: Kementerian Ketenagakerjaan.

United States Army Natick., 1989. Anthropometric Survey of U.S. Army Personel: Summary Statistic.US: Army Research, Development and Engineering Center, Natick. Tersedia di http:// www.ncbi.nlm.nih.gov/pubmed/18479294.[Sitasi 9 Juli 2017].

Wignjosoebroto, S., 1995. Ergonomi: Studi Gerak dan Waktu. Surabaya: Guna Widy. 